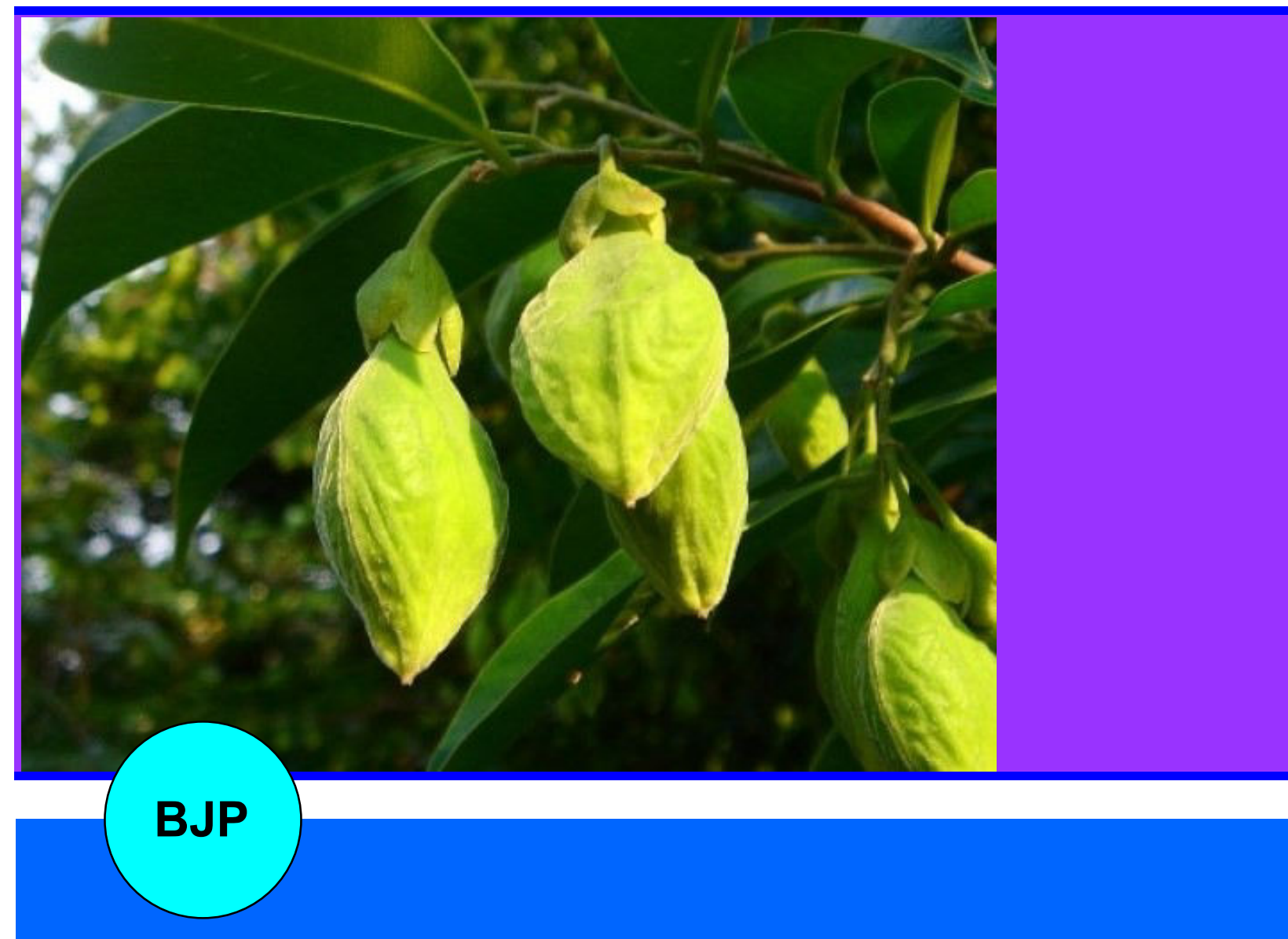

Bangladesh Journal of Pharmacology

Research Article

Analysis of essential oil of eaglewood tree (Aquilaria agallocha Roxb.) by gas chromatography mass spectrometry 


\title{
Analysis of essential oil of eaglewood tree (Aquilaria agallocha Roxb.) by gas chromatography mass spectrometry
}

\author{
Md. Nazrul Islam Bhuiyan, Jaripa Begum and Md. Nurul Huda Bhuiyan
}

BCSIR Laboratories, P.O. Chittagong Cantonment, Chittagong 4220, Bangladesh.

\begin{tabular}{|c|c|}
\hline \multicolumn{2}{|l|}{ Article Info } \\
\hline $\begin{array}{l}\text { Received: } \\
\text { Accepted: } \\
\text { Available Online: }\end{array}$ & $\begin{array}{r}22 \text { May } 2008 \\
18 \text { July } 2008 \\
14 \text { August } 2008\end{array}$ \\
\hline \multicolumn{2}{|c|}{ DOI: 10.3329/bjp.v4i1.851 } \\
\hline $\begin{array}{l}\text { Cite this article: } \\
\text { Bhuiyan MNI, } \\
\text { MNH. Analysis } \\
\text { eaglewood tree } \\
\text { Roxb.) by gas ch } \\
\text { spectrometry. Ba } \\
\text { col. } 2009 ; 4: 24-28 .\end{array}$ & $\begin{array}{l}\text { um J, Bhuiyan } \\
\text { essential oil of } \\
\text { uilaria agallocha } \\
\text { hatography mass } \\
\text { adesh J Pharma- }\end{array}$ \\
\hline
\end{tabular}

\begin{abstract}
The study was carried out to find out the differences in composition of oils obtained from healthy, naturally infected and artificially screws wounds eaglewood (Aquilaria agallocha Roxb.) using gas chromatography mass spectrometry analysis. Natural healthy plants agar contained octacosane (19.8\%), naphthalene, 1,2,3,5,6,7,8,8a-octahydro-1,8a-dimethyl-7-(1-methylethenyl)-, [1R-(1.alpha.,7.beta.,8a.alpha.)]- (12.7\%), 5-isobutyramido-2-methyl pyrimidine $(13.5 \%)$, caryophyllene oxide $(11.3 \%)$ and (.+-.)-cadinene $(5.5 \%)$. Natural infected plants agar (super agar) contained cycloheptane, 4-methylene-1methyl-2-(2-methyl-1-propen-1-yl)-1-vinyl- (46.17\%), caryophyllene oxide $(33.0 \%)$ and 7-isopropenyl-4a-methyl-1-methylenedecahydronaphthalene $(20.8 \%)$. Artificially screw injected plants agar contained diisooctyl phthalate $(72.0 \%)$, 1H-cycloprop[e]azulen-4-ol, decahydro-1,1,4,7-tetramethyl-, [1ar(1a.alpha.,4.beta.,4a.beta., 7.alpha., 7a.beta., 7b.alpha.)]- (9.2\%), hexadecanoic acid (7.1\%), naphthalene, 1,2,3,5,6,7,8,8a-octahydro-1,8a-dimethyl-7-(1methylethenyl)-, [1R-(1.alpha.,7.beta.,8a.alpha.)]- (6.5\%) and aristolene (5.4\%). This study showed a marked difference in the oil compositions among the treatments with regards to their quality.
\end{abstract}

\section{Introduction}

Agar, a valuable aromatic oleoresinous deposit found in the stems of Aquilaria agallocha Roxb. (syn. Acquilaria malaccensis Lamk., family: Thymelaeaceae) is available in Bangladesh, East India and other parts of South East Asia (Gibson, 1977). The present investigation includes essential oils and identification of fungal isolates from three samples of agar collected in the Sylhet region of Bangladesh. The eaglewood tree A. agallocha is a precious floral wealth of Indian subcontinents like Bangladesh (Anonymous., 1948). The resinous patches of fragrant wood of the plant known as 'agar' is used as incense in Egypt, Arabia and throughout the northeast part of Bangladesh where it can be found. The oil obtained from agar is described as a stimulant, cardiac tonic and carminative. It is also used in the cosmetic and pharmaceutical industries.

Agarwood (jinkoh in Japanese) is an oriental medicine for use as a sedative (Okugawa et al., 1993). Agar is considered to be a pathological product produced by fungal invasion of the host (Qi Shu-Yuan et al., 1992). Since 1938, few workers have been studying about agar formation and reported the agar zones to be associated with mold and decay fungi (Bose, 1938; Bhattacharyya et al., 1952; Jalaluddin, 1977; Venkataramanan et al., 1985; Beniwal, 1989; Tamuli et al., 2000ab; Mitra and Gogoi, 2001). Among different fungal species reported to be associated with agar zones, few could exhibit pathogenesis with the development of disease symptoms while others seem to be of saprophytic nature in different eco-geographical conditions. Studies on the oil of infected $A$. agallocha were made by various 
workers (Maheshwari et al., 1963; Varma et al., 1965; Paknikar and Naik, 1975; Thomas and Ozainne, 1976; Pant and Rastogi, 1980; Bhandari et al., 1982; Nagashima et al., 1983; Ishihara et al., 1991, 1993). Maheshwari et al. (1963) isolated three new sesquiterpenic furanoids of the selinane group from agarwood oil, obtained from the fungus infected plant and their structures and absolute configurations determined by degradative studies and physical measurements. Varma et al. (1965) examined that degradative studies and physical measurements supported by an unambiguous synthesis of the derived ketone have led to the assignment of a novel spiroskeleton to agarospirol, a sesquiterpene alcohol isolated from the essential oil of infected agarwood. Paknikar and Naik (1975) reported that on hydrogenation of aagarofuran and $\beta$-agarofuran the same dihydroagarofuran was obtained. Thomas and Ozainne (1976) reported some naturally occurring dihydroagarofuran and isodihydroagarofuran to unequivocally show that the dihydroagarofuran found was indeed dihydro- $\beta$ agarofuran and isodihydroagarofuran was isodihydro$\beta$-agarofuran; two separate compounds. Pant and Rastogi (1980) and Bhandari et al. (1982) isolated a new sesquiterpene, agarol and a couinarinolignan, aquillochin, respectively, from the oil of agarwood. Nagashima et al. (1983) further characterized the presence of two more sesquiterpene alcohols, jinkohol II and jinkoh- eremol, from the Indonesia agar wood oil. Nakanishi et al. (1984) again reported that a benzene extract of an Indonesian sample of 'Jinkoh' agarwood was found to contain a-agarofuran, 10-epi- $\gamma-$ eudesmol and oxo-agarospirol. Ishihara et al. (1991) characterized seven new sesquiterpenes based on the guaiane skeleton in a sample of agarwood oil. Five new eudesmane sesquiterpenes and three other compounds further characterized by Ishihara et al. (1993) in a sample of agarwood extract produced in the laboratory from A. agallocha of Vietnamese origin. Vesiculararbuscular myccorhizal association in the tree species and changes in amino acid composition due to pathogenesis were also studied by Tamuli et al. (2002a, 2002b). Tamuli et al. (2005) investigate the difference in composition of oils obtained from healthy, naturally infected and artifically inoculated eaglewood using GC and GC-MS analyses. This investigation shows a marked difference in the oil compositions among the treatments with regards to their quality. Valerianol $(3.0 \%)$ and tetradecanoic acid $(7.1 \%)$ contents were recorded higher in the oils of naturally infected plants than in that of healthy ones ( 0.1 and $6.9 \%$ respectively). Pentedecanoic acid was totally absent in the oils of healthy plants, whereas it was found in a greater amount $(6.8 \%)$ in the oil of naturally infected plants. In contrast dodecanoic acid (3.1\%), pentedecanoic acid $(6.2 \%)$, hexadecanoic acid $(31.5 \%)$ and octadecanoic acid were found in the oils of healthy plants, while the oils obtained from naturally infected plants contained lower amounts of these components (2.3, 4.8, 20.0 and $1.0 \%$ respectively). The oils obtained from the inoculated plants showed almost similar distribution of the components with healthy plants. So far the qualitative study of the oils of healthy and wounds eaglewood has yet to be investigated. The present investigation was, therefore, undertaken to study the qualitative differences in the oils obtained from healthy, naturally infected and artificially screw wounds eaglewood. This paper reports the results obtained by GC-MS on A. agallocha oils.

\section{Materials and Methods}

\section{Plant material}

A. agallocha was collected from the Sylhet of Bangladesh during November 2007. The specimen was identified by Dr. Mohammad Yusuf (Taxonomist), BCSIR Labs. Ctg. One-voucher specimen (Y-699) was deposited in the herbarium of BCSIR Laboratory, Chittagong.

\section{Extraction of essential oil}

Essential oils were extracted from healthy plants, natural fungal inoculated plants (super agar) and artificial screws injected plants. All those three types of plant materials were collected from Sylhet, crashed and dried and then grinned individually. The grinded materials were soak in distilled water up to 14 days and filtered them separately. The filtrate water mixtures were placed with Clevenger-type apparatus individually for isolation of oils by hydrodistillation (Clevenger, 1928). After 72 hours essential oils were collected separately and dried over anhydrous sodium sulfate. The oils were then stored in sealed container under refrigeration prior to analysis.

\section{GC-MS analysis}

The three types of essential oil in different types of woods from $A$. agallocha were analyzed by GC-MS electron impact ionization (EI) method on GC-17A gas chromatograph (Shimadzu) coupled to a GC-MS QP 5050A mass spectrometer (Shimadzu); fused silica capillary column (30 m x $2.5 \mathrm{~mm} ; 0.25 \mathrm{~mm}$ film thickness), coated with DB-5 ms (J \& W); column temperature $100^{\circ}$ $\mathrm{C}(2 \mathrm{~min})$ to $250^{\circ} \mathrm{C}$ at the rate of $3^{\circ} \mathrm{C} / \mathrm{min}$; carrier gas, helium at constant pressure of $90 \mathrm{Kpa}$. Acquisition parameters full scan; scan range 40-350 amu.

\section{Identification of the compounds}

Compound identification was done by comparing the NIST library data of the peaks with those reported in literature, mass spectra of the peaks with literature data. Percentage composition was computed from GC peak areas on with DB-5 ms column without applying correction factors. 


\section{Results and Discussion}

The oil of healthy, naturally infected and artificially screws injected plants of A. agallocha contained $0.15 \%$ $(\mathrm{w} / \mathrm{v}), 0.8 \%(\mathrm{w} / \mathrm{v})$ and $0.4 \%(\mathrm{w} / \mathrm{v})$ oil respectively. The oils were colorless, having pleasant smell. The oil of healthy, naturally infected and artificially screws

\begin{tabular}{|c|c|c|}
\hline \multicolumn{3}{|c|}{ Table I } \\
\hline \multicolumn{3}{|c|}{$\begin{array}{l}\text { Constituents of essential oil from natural healthy } \\
\text { agar }\end{array}$} \\
\hline $\begin{array}{l}\text { SL } \\
\text { No. }\end{array}$ & Name of the components & $\%$ \\
\hline 1 & $\begin{array}{l}\text { Tricyclo[5.2.2.0(1,6)] undecan-3-ol, 2- } \\
\text { methylene-6,8,8-trimethyl- }\end{array}$ & 0.9 \\
\hline 2 & Alloaromadendrene oxide-(1) & 0.8 \\
\hline 3 & (-)-Spathulenol & 1.4 \\
\hline 4 & 6,9-Octadecadiynoic acid, methyl ester & 0.8 \\
\hline 5 & $\begin{array}{l}\text { 2-Naphthalenemethanol, 1,2,3,4,4a,5,6,7- } \\
\text { octahydro-.alpha.,.alpha.,4a,8-tetramethyl- } \\
\text {, (2R-cis)- }\end{array}$ & 3.1 \\
\hline 6 & Patchoulene & 1.4 \\
\hline 7 & $\begin{array}{l}\text { Naphthalene, 1,2,3,5,6,7,8,8a-octahydro- } \\
\text { 1,8a-dimethyl-7-(1-methylethenyl)-, [1R- } \\
\text { (1.alpha.,7.beta.,8a.alpha.)]- }\end{array}$ & 12.7 \\
\hline 8 & $\begin{array}{l}\text { Azulene, 1,2,3,3a,4,5,6,7-octahydro-1,4- } \\
\text { dimethyl-7-(1-methylethenyl)-, [1R- } \\
\text { (1.alpha.,3a.beta.,4.alpha.,7.beta.)]- }\end{array}$ & 1.1 \\
\hline 9 & Aristolene & 3.9 \\
\hline 10 & Eremophilene & 1.0 \\
\hline 11 & 5-Isobutyramido-2-methyl pyrimidine & 13.5 \\
\hline 12 & Isolongifolene, 9,10-dehydro- & 1.5 \\
\hline 13 & Diphenoxylic acid & 1.6 \\
\hline 14 & Neoisolongifolene, 8,9-dehydro- & 1.7 \\
\hline 15 & Isolongifolen-5-one & 1.7 \\
\hline 16 & $\begin{array}{l}\text { Naphthen-1-acetic acid, 8-methoxy-.alpha. } \\
\text {-methyl }\end{array}$ & 1.5 \\
\hline 17 & 3-Hydroxy-7-methoxy-2-naphthoic acid & 0.8 \\
\hline 18 & $\begin{array}{l}\text { Propanoic acid, 3-(diisopropylphosphino)- } \\
\text {, methyl ester }\end{array}$ & 0.9 \\
\hline 19 & $\begin{array}{l}\text { 3-Methoxy-6,7,8,9-tetrahydro- } \\
\text { dibenzofuran-2-ol }\end{array}$ & 1.1 \\
\hline 20 & (.+-.)-Cadinene & 5.5 \\
\hline 21 & Longiverbenone & 1.2 \\
\hline 22 & Caryophyllene oxide & 11.3 \\
\hline 23 & $\begin{array}{l}\text { (6-Hydroxymethyl-2,3-dimethylphenyl) } \\
\text { methanol }\end{array}$ & 1.3 \\
\hline 24 & $\begin{array}{l}\text { 9-[4-[1,3-Diphenyl-2-imidazolidinyl]-2,3-O } \\
\text {-[1-methylethylidene]-.beta.-d }\end{array}$ & 0.8 \\
\hline 25 & a-Cedrene oxide & 1.0 \\
\hline 26 & Viridiflorol & 1.8 \\
\hline 27 & Hexadecanoic acid & 1.3 \\
\hline 28 & Octacosane & 19.8 \\
\hline 29 & Diisooctyl phthalate & 2.2 \\
\hline
\end{tabular}

Table I

\begin{tabular}{|c|c|c|}
\hline \multicolumn{3}{|c|}{$\begin{array}{l}\text { Constituents of essential oil from nature infected } \\
\text { isolated agar (super agar) }\end{array}$} \\
\hline $\begin{array}{l}\text { SL } \\
\text { No. }\end{array}$ & Name of the components & $\%$ \\
\hline 1 & $\begin{array}{l}\text { 7-Isopropenyl-4a-methyl-1- } \\
\text { methylenedecahydronaphthalene }\end{array}$ & 20.8 \\
\hline 2 & $\begin{array}{l}\text { Cycloheptane, 4-methylene-1-methyl-2- } \\
\text { (2-methyl-1-propen-1-yl)-1-vinyl- }\end{array}$ & 46.2 \\
\hline 3 & Caryophyllene oxide & 33.0 \\
\hline
\end{tabular}

\begin{tabular}{|c|c|c|}
\hline \multicolumn{3}{|c|}{ Table III } \\
\hline \multicolumn{3}{|c|}{$\begin{array}{c}\text { Constituents of essential oil from artificial screws } \\
\text { injected agar }\end{array}$} \\
\hline $\begin{array}{l}\text { SL } \\
\text { No. }\end{array}$ & Name of the components & $\%$ \\
\hline 1 & $\begin{array}{l}\text { Naphthalene, 1,2,3,5,6,7,8,8a-octahydro- } \\
\text { 1,8a-dimethyl-7-(1-methylethenyl)-, [1R- } \\
\text { (1.alpha.,7.beta.,8a.alpha.)]- }\end{array}$ & 6.5 \\
\hline 2 & Aristolene & 5.4 \\
\hline 3 & $\begin{array}{l}\text { 1H-Cycloprop[e]azulen-4-ol, decahydro } \\
\text {-1,1,4,7-tetramethyl-, [1ar- } \\
\text { (1a.alpha.,4.beta.,4a.beta., } \\
\text { 7.alpha.,7a.beta.,7b.alpha.)]- }\end{array}$ & 9.2 \\
\hline 4 & Hexadecanoic acid & 7.1 \\
\hline 5 & Diisooctyl phthalate & 72.0 \\
\hline
\end{tabular}

injected plant agar was analyzed by GC-MS. Twenty nine compounds in the healthy oil, three compounds in the super oil and five compounds in the artificial screws infected oil were identified. The data are shown in Table I, II and III respectively. Investigation showed a marked difference between the oils obtained from naturally infected and healthy plants with regards to their quality. Healthy plants oil contained octacosane $(19.8 \%)$, naphthalene, $1,2,3,5,6,7,8,8 \mathrm{a}$-octahydro-1,8adimethyl-7-(1-methylethenyl)-, [1R-(1.alpha.,7.beta., 8a.alpha.)]- (12.7\%), 5-isobutyramido-2-methyl pyrimidine $(13.5 \%)$, caryophyllene oxide $(11.3 \%)$ and (.+-.)-cadinene $(5.5 \%)$. Natural infected plants (super agar) contained cycloheptane, 4-methylene-1-methyl-2(2-methyl-1-propen-1-yl)-1-vinyl- (46.2\%), caryophyllene oxide $(33.0 \%)$ and 7-Isopropenyl-4amethyl-1-methylenedecahydronaphthalene (20.8\%). Artificially screw injected plants contained diisooctyl phthalate $(72.0 \%), \quad 1$ H-cycloprop[e]azulen-4-ol, decahydro-1,1,4,7-tetramethyl-, [1ar-(1a.alpha.,4.beta., 4a.beta., 7.alpha., 7a.beta., 7b.alpha.)]- (9.2\%), hexadecanoic acid (7.1\%), naphthalene, 1,2,3,5,6,7,8,8aoctahydro-1,8a-dimethyl-7-(1-methylethenyl)-, [1R(1.alpha.,7.beta.,8a.alpha.)]- (6.5\%) and aristolene $(5.4 \%)$. The oils obtained from the inoculated plants showed almost similar distribution of the components. But some of the components were found in the oils of artificially inoculated plants including naturally 
infected whereas those are totally absent in the oil of healthy plants. 7-Isopropenyl-4a-methyl-1-methylenedecahydronaphthalene and cycloheptane, 4-methylene1-methyl-2-(2-methyl-1-propen-1-yl)-1-vinyl- were totally absent in the oil of healthy plants and natural infected plants oil. It was observed that the characteristic components of agarwood oil were found to be lower in the oils obtained from healthy samples. The oils obtained from artificially inoculated agarwood have no such differences with the oils of healthy wood though little changes were observed. This may indicate that naturally infected type of agarwood would not be achieved by artificially screws injected plants oil. The observations made by us showed that the microflorais of great importance in production of specialized type of agarwood for best quality agar oil. However, there may exist variants or eco-types within the agarwood plant species. If natural variant or type exists within the plant species, the fungal pathogens might be host type specific or variant specific. If it is so, there may exist specific host variant pathogen/host type-pathogen relationship, which determines the success of artificial inoculation. Therefore, identification of natural variant or eco-type and the specific host-pathogen relationship under different ecological conditions is expected to give clue for unraveling the secret of agar formation. Then only artificial supplement of inoculum to the specific host might give positive result for induction of disease in the plant.

\section{Conclusion}

A. agallocha, may be utilized as a source of natural octacosane, cycloheptane, 4-methylene-1-methyl-2-(2methyl-1-propen-1-yl)-1-vinyl- and diisooctyl phthalate respectively.

\section{References}

Anonymous. The wealth of India: Raw materials. Vol 1. New Delhi, Publication and Information Directorate, CSIR, 1948, pp 88-90.

Beniwal BS. Silvical characteristics of Aquilaria agallocha Roxb. Indian Forest. 1989; 115: 17-21.

Bhandari P, Pant R, Rastogi RP. Aquillochin: A coumarinolignan from Aquilaria agallocha. Phytochemistry 1982; 21: 214749 .

Bhattacharyya B, Datta A, Baruah HK. On the formation and development of agaru in Aquilaria agallocha. Sci Cult. 1952; 18: $240-41$.

Bose SR. The nature of 'Agaru' formation. Sci Cult. 1938; 4: 8991.

Clevenger JF. Apparatus for determination of volatile oil. J Amer Pharm Assoc. 1928; 17: 346.
Gibson IAS. The role of fungi in the origin of oleoresin deposits (Agaru) in the wood of Aquillaria agallocha (Roxb.). Bano Biggyn Patrika. 1977; 6: 16-26.

Ishihara M, Tsuneya T, Uneyama K. Fragrant sesquiterpenes from agarwood. Phytochemistry 1993; 33: 1147-55.

Ishihara M, Tsuneya T, Uneyama K. Guaiene sesquiterpenes from agarwood. Phytochemistry 1991; 30: 3343-47.

Jalaluddin M. A useful pathological condition agarwood. Econ Bot. 1977; 31: 222-24.

Maheshwari ML, Jain TC, Bates RB, Bhattacharyya SC. Structure and absolute configuration of a-agarofuran, $\beta$-agarofuran and dihydroagarofuran. Tetrahedron 1963; 19: 107990 .

Mitra J, Gogoi P. Fungi associated with the diseased wood (agarwood/agaru) of Aquilaria agallocha Roxb. (Family: Thymelaeaceae) grown in Assam. Proceedings of seminar on scope and dimension of agarplantation in NE region Ahmed M, Gogoi P, Ahmed GU, Hojai AATMA (eds). India, 2001, pp 61-69.

Nagashima T, Kawasaki I, Yoshida T, Nakanishi T, Yoneda K, Miura I. New Sesquiterpenoids from agarwood. Paper IXth International essential oil congress. Singapore 1983, pp 1216.

Nakanishi T, Yamagata E, Yoneda K, Nagashima T, Kawasaki I, Yoshida T, Mori H, Miura I. Three fragrant sesquiterpenes of agarwood. Phytochemistry 1984; 22: 2066-67.

Okugawa H, Ueda R, Matsumoto K, Kawanishi K, Kato A. Effect of Agarwood on the central nervous system in mice. Planta Medica. 1993; 59: 32-36.

Paknikar SK, Naik CG. Stereochemistry of dihydroagarofurans and evidence in support of the structure of 4,11- epoxy-ciseudesmane. Tet Lett. 1975; 15: 1293-94.

Pant P, Rastogi RP. Agarol, a new sesquiterpene from Aquilaria agallocha. Phytochemistry 1980; 19: 1869-70.

Yuan QS, Yau LB, Feng ZL, Ling LB. Formation of oxoagarospirol in Aquilaria sinensis. Plant Physiol Commun. 1992; 28: 336-39.

Tamuli P, Boruah P. Changes in amino acids in agarwood plant under pathological condition. Geobios 2002a; 29: 24143.

Tamuli P, Boruah P. Vesicular-arbuscular mycorrhizal (VAM) association of agarwood tree in Jorhat district of the Brahmaputra Valley. Indian Forest. 2002b; 128: 991-94.

Tamuli P, Boruah P, Nath SC. Essential oil of eaglewood tree: A product of pathogenisis. J Essent Oil Res. 2005; 17: 601-04.

Tamuli P, Boruah P, Nath SC, Samanta R. Fungi from diseased agarwood tree (Aquilaria agallocha Roxb.): Two new records. Adv Forest Res India 2000a; 22: 182-87.

Tamuli P, Boruah P, Nath SC, Samanta R. Mycofloral study on the phyllosphere and soil of agarwood tree plantation. U.G.C. Sponsored seminar on conservation of biodiversity, Assam, 2000b; $p 5$.

Thomas AF, Ozainne M. The stereochemistry of the dihydroagarofurans. Tet Lett. 1976; 20: 1717-18. 
Varma KR, Maheshwari ML, Bhattacharyya SC. The constitution of agarospisol, a sesquiterpenoid with a new skeleton. Tetrahedron 1965; 21: 115-38.
Venkataramanan MN, Borthakur R, Singh HD. Occurrence of endotrophic myccorhizal fungus in agarwood plant Aquilaria agallocha Roxb. Curr Sci. 1985; 54: 928.

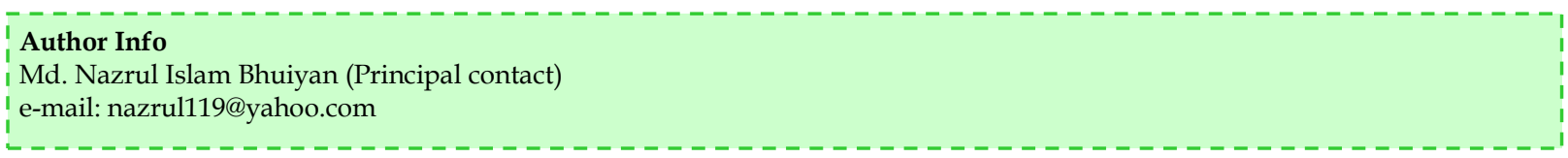

